\title{
Analysis of Online Food Delivery Process by Zomato using Data Science
}

\author{
Dr. Dharmpal Singh ${ }^{1} \mid$ Saurav Srivastav $^{1} \mid$ Shweta Shree $^{1} \mid$ Simran Shrivastava $^{1} \mid$ Soma Sharma ${ }^{1}$ \\ ${ }^{1}$ Department of Computer Science \& Engineering, JIS College of Engineering, Nadia, Kalyani-741235, West Bengal
}

To Cite this Article

Dr. Dharmpal Singh, Saurav Srivastav, Shweta Shree, Simran Shrivastava and Soma Sharma, "Analysis of Online Food Delivery Process by Zomato using Data Science", International Journal for Modern Trends in Science and Technology, 6(8S): 125-127, 2020.

Article Info

Received on 16-July-2020, Revised on 15-August-2020, Accepted on 25-August-2020, Published on 28-August-2020.

\section{ABSTRACT}

The whole world is circumference with the unseen covering of artificial intelligence, Internet of Thing, 5G, and many more fast forward technologies which could assist the human to do their work in almost no time. Today the whole globe is in stalemate position due to the pandemic created by an airborne virus, people all over the globe are preferring online platform to do all their essential work and avoiding to go to the marketplaces or to the workplace due to the spread of airborne disease. The present world facing the deteriorating situation due to the spread of the corona virus and the whole country is facing the tough time due to lockdown which has put a barrier in the dream coming true of the multilateral development of any country.

The most important and basic needs of today are the procurement of the food items. This is the ultimate nature of humans that they like to try different cuisines. As per the report, the online food delivery market in the country is growing at 15\% which is in comparison to the global growth rate of $9.01 \%$. Some of the biggest giant players of online marketing in food are Swiggy, Zomato, Uber eats, and so on. The need of analyzing the Zomato dataset is to get a clear view of the factors affecting the accumulated rating of each restaurant, establish different types of restaurants at different places.

This paper demonstrates the data analysis on the Zomato dataset assisting website in order to help in better ideas for further marketing strategy by using the tool of data science. This analysis caters the needs of people who are striving to get the best cuisine in the country and which locality of that country serves that cuisine with maximum number of restaurants. Normal people as well as developers both have advantages of this analysis.

Keywords - Data science, regression, data analysis, Zomato.

\section{INTRODUCTION}

Zomato is one of the most important online foods ordering business in today's generation. It is a kind of an online guide book for users of Zomato. This site mainly focuses on the restaurants of Bangalore as well as Chennai and helps the user categorized the different places and choose the best among them in means of menus, dishes, localities, and several other mediums.

In order to understand the data set, there is a necessity of procedure by means of machine learning concepts which would help in analyzing the data set in all different aspects. We could develop marketing strategy by noticing the client 
comfort through the result of deep analysis performed by data science.

\section{LITERATURE SURVEY:}

Data science is the study of the systematic removal of indistinct and useful patterns and knowledge from data, towards research advancement, organizational decision-making which enables a computer-controlled society.

Accordingly, scholars advocate for data-intensive science, discovery science or data-driven science, in which:

- It is suited to make sense of massive interconnected datasets, overcoming problems of small samples, and scarce data.

- Interdisciplinary research is promoted.

- Complete models and theories about complex systems, rather than elements of it, are possible.

The data collected for this research is from the secondary data sources (Kaggle). Since the complexity and quantity of the data leads, need to perform data preprocessing in order to get an accurate result. The first step in data analysis is to prevent missing data, then the co-relation method is performed to foremost the data visualization process.

\section{OBJECTIVE}

The main objectives of this data analysis are as follows:

- Find the most popular restaurant in Bangalore/Chennai.

- Find the most popular cuisines in Bangalore/ Chennai

- Compare between the online and offline order.

- frequency vs. restaurant type

- It predicts the no. of restaurants vs. the location of the city

- The data analysis part is exemplified through a website to forecast it publicly.

\section{METHODOLOGY}

We have completed this project by using the python programming. The very first part which is done in the python programming is importing the packages. There are mainly five packages that are used commonly such as Numpy, Matplotlib, Scikit-learn, Pandas, and Seaborn.
The algorithms which are used are mentioned below:

- Linear regression

- Logistic regression

- Decision tree regression

- Random forest regression.

\section{SCREENSHOTS OF THE GRAPHS}

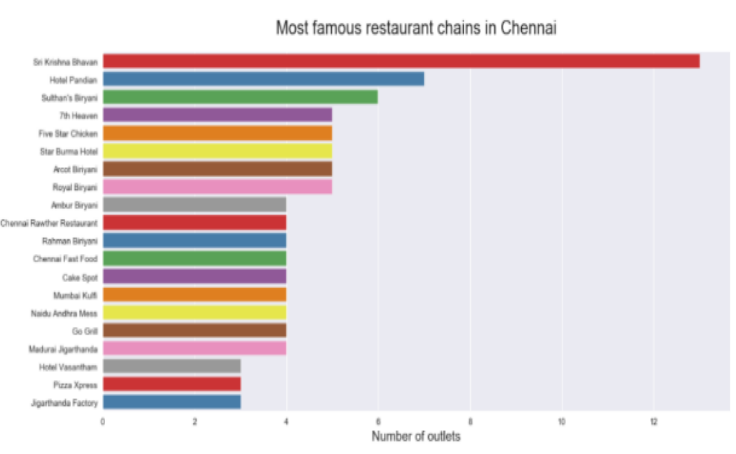

Fig (a): Most famous restaurants in Chennai.

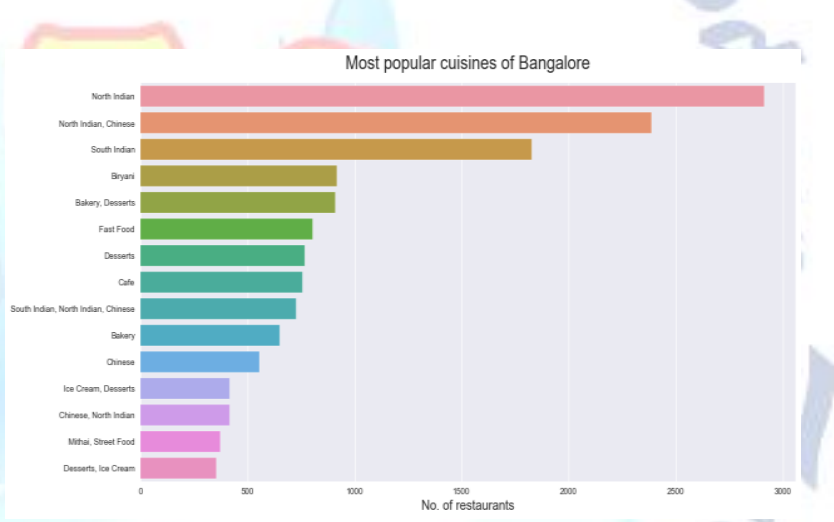

Fig (b): Most popular cusines of Bangalore

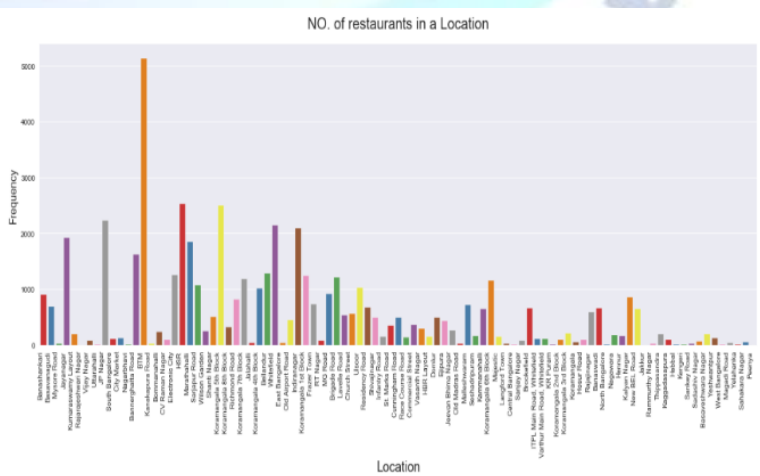

Fig (c): No. of restaurants in a location 


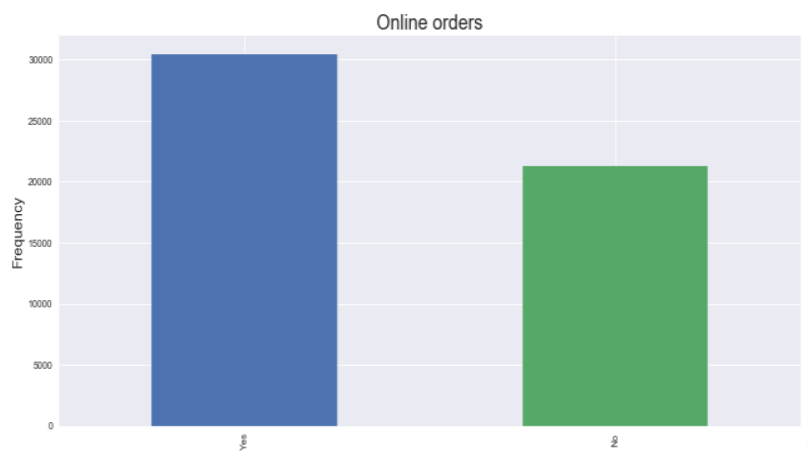

Fig (d): Online vs offline order

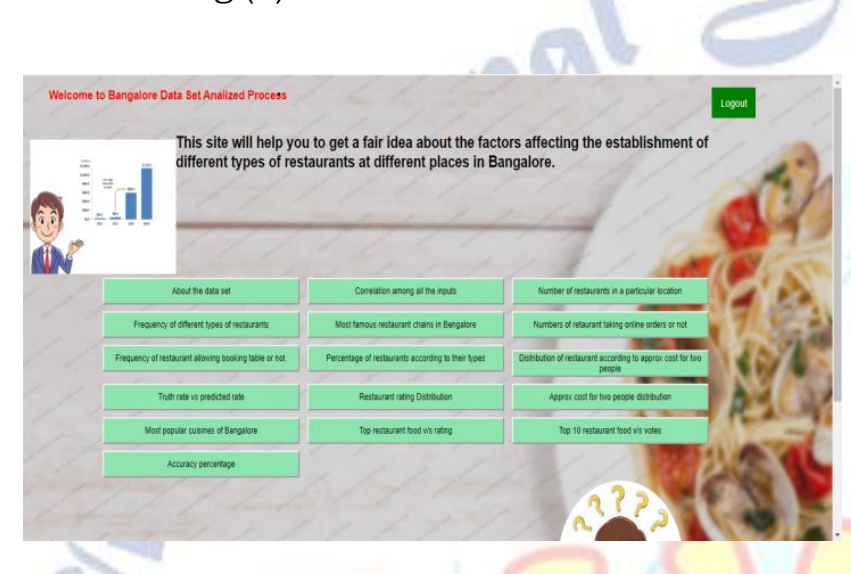

Fig (e): Website page of Bangalore data analysis

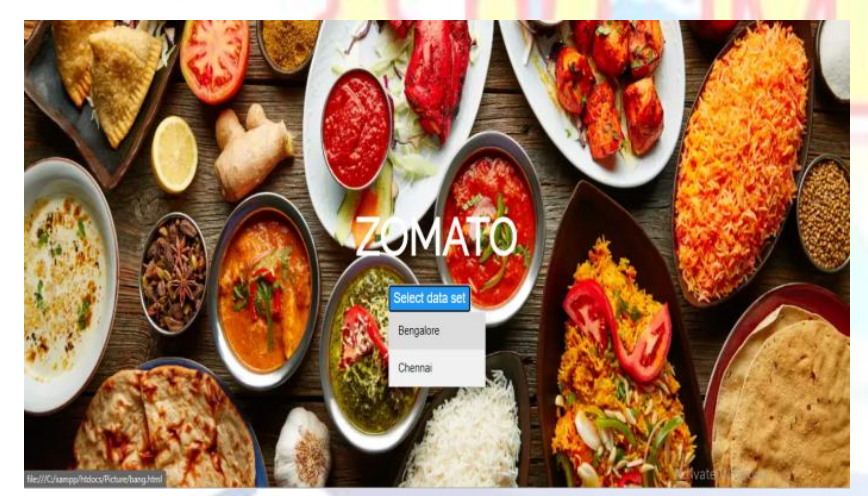

Fig (f): Front Page of the Website

\section{REFERENCE}

[1] https://www.kaggle.com/

[2] https://www.researchgate.net/publication/323393464_Da ta_Science_Literature_Review_State_of_Art

[3] https://datascience.codata.org/articles/10.5334/dsj-2019 $-014 /$

[4] http://indusedu.org/pdfs/IJREISS/IJREISS_2957_35179. pdf

[5] http://ijrar.com/upload_issue/ijrar_issue_20542895.pdf

[6] https://theaims.ac.in/resources/online-food-service-in-ind ia-an-analysis.html

[7] http://ieomsociety.org/ieomdetroit/pdfs/49.pdf

\section{CONCLUSION}

- The most popular cuisines of Bangalore are North Indian Chinese and South Indian foods.

- The most popular restaurants in Chennai are Shri Krishna Bhavan, Hotel Pandian, and Sultan Briyani.

- The accuracy percentage of Bangalore dataset is $84 \%$ and that of Chennai is $99 \%$

- Orders placed online is $62 \%$ and offline order is $29 \%$. 